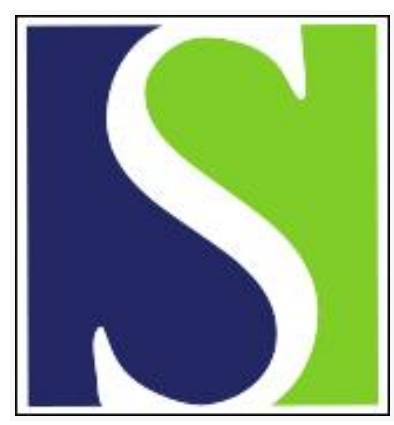

Scand J Work Environ Health 1987;13(4):323-325

https://doi.org/10.5271/sjweh.2034

Issue date: Aug 1987

A new depth-sense esthesiometer. A comparative study on sensitivity.

by Chatterjee DS

Affiliation: Ford Motor Company Limited, Essex, United Kingdom.

This article in PubMed: www.ncbi.nlm.nih.gov/pubmed/3433032

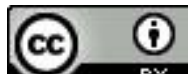




\title{
A new depth-sense esthesiometer
}

\section{A comparative study on sensitivity}

\author{
by Durga S Chatterjee, MB, BS, DIH, MFOM ${ }^{1}$
}

\begin{abstract}
CHATTERJEE DS. A new depth-sense esthesiometer: A comparative study on sensitivity. Scand $J$ Work Environ Health 13 (1987) 323-325. The structure and functions of a depth-sense esthesiometer have been described. Unlike the prototype designed by Renfrew, the new instrument is so fabricated that the speed and the directions of its movements, and the pressure applied by the finger, can be constantly controlled. In addition, it provides an automatic measurement of depth-sense thresholds with greater accuracy. Thirtythree normal subjects and nine patients were examined with both instruments. With the new esthesiometer all normal hands, as expected, showed normal results, but, with the Renfrew instrument, 12 of these 66 hands $(18 \%)$ showed abnormal results. Similarly, on examination of the hands of the nine patients, the new instrument showed equally improved reliability.
\end{abstract}

Key terms: dial test indicator, digital peak indicator, electromyography, precision direct current motor, strain gauge sensor, vibration-induced white finger, wedges.

Decreased tactility has proved to be one of the most common features $(2,3,7)$ of vibration-induced white finger (VWF). More recently, investigations have shown that acute impairment of tactile sensibility caused by vibration exposure is very probably due to the depression of the excitability of the mechanoreceptive afferent units (4).

However, to date, no objective test has been found to diagnose VWF on an individual basis. Of the clinical tests the measurement of depth-sense thresholds by the Renfrew esthesiometer (5) has shown statistically the greatest significant difference between vibrationexposed and unexposed groups. The present study was aimed at designing a more reliable and sensitive esthesiometer through the introduction of modifications that would make (i) the pressure applied by the finger easily regulated, (ii) the speed and direction of the movements of the instrument constantly controllable, and (iii) the threshold of depth-sense measurable with greater ease and accuracy.

\section{Materials and methods}

\section{Esthesiometer}

Basically the new esthesiometer (figure 1) consists of two tapered wedges. One is used to create the perception of depth sense (examining wedge), and the other measures the threshold perceived (indicator wedge).

Each wedge is $100 \mathrm{~mm}$ long and shaped like a truncated inverted letter $T$, its upper surface having a ridge $2 \mathrm{~mm}$ wide. The ridge is centrally disposed along the length and tapers from the thickness of $1 \mathrm{~mm}$ at one end to zero at the other.

\footnotetext{
1 Ford Motor Company Limited, Essex, United Kingdom.
}

Reprint requests to: Dr DS Chatterjee, Ford Motor Company Limited 15/190, Research \& Engineering Centre, Laindon, Basildon, Essex SS15 6EE, UK.
At the examining end, the wedge is made of plastic, which is a poor conductor of heat, and at the indicator end it is made of brass. The two pieces are connected by a brass rod $6 \mathrm{~mm}$ in diameter, $85 \mathrm{~mm}$ long and lock-nutted. Thus the two wedges work in unison.

Across the base, $20 \mathrm{~mm}$ in from the examining end of the wedge, a bridge is constructed to allow the finger to rest on the ridge. For $230 \mathrm{~mm}$ along the base a vertical bridge is fitted of such dimension as to hold a standard $10-\mathrm{mm}$ dial test indicator capable of reading to $0.01 \mathrm{~mm}$. At the end of the indicator wedge a vertical shaft is fitted which enables the wedges to be moved forward and backward by a precision direct current motor fixed to the wooden base on which the instrument is mounted.

The direct current motor incorporates a self-supporting cylindrical ironless rotor with a very low inertial mass which gives a fast and smooth response characteristic of output torque versus speed. An ovoid gearbox [Radio Spares (RS) stock no 336.264 , gear ratio $160: 1$, approximate efficiency $66 \%$ ] is attached to the motor.

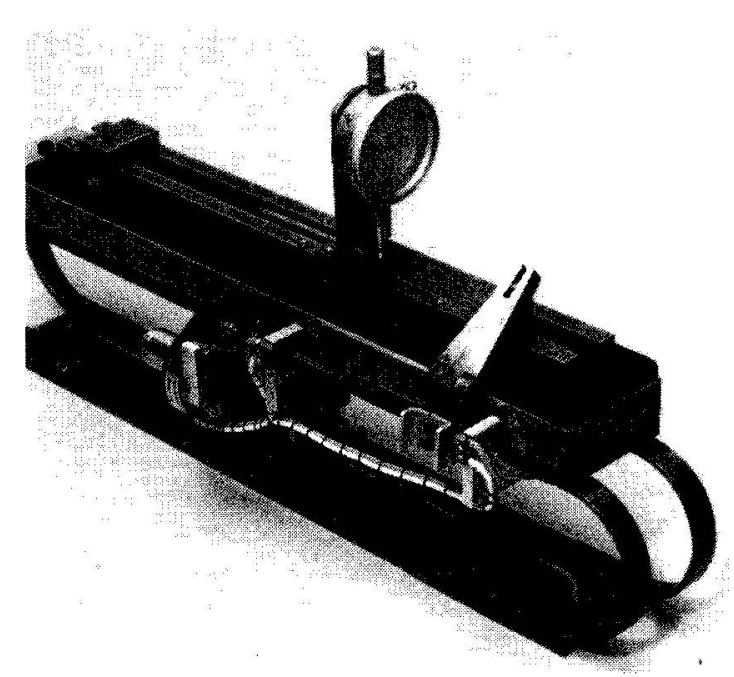

Figure 1. The new esthesiometer. 
A specially designed servo mounting kit is used to couple the precision motor/gear box assemblies mechanically to an RS conductive plastic servo-potentiometer. The whole unit is supported by a metal frame into which a strain gauge sensor is inserted. The frame consists of two electric sockets, one for connecting it to the control box and the other to the digital peak indicator.

\section{Digital peak indicator}

A GSE model 229-D digital peak indicator is used to monitor the pressure applied by the finger through the strain-gauge sensor. It is $15 \times 22 \times 15 \mathrm{~cm}$ in size and weighs $2.5 \mathrm{~kg}$. Its specifications include a $16.8-\mathrm{V}$ rechargeable 8 -h life battery, external and internal shunt calibration supplied to simulate engineering units, instrument accuracy of $\pm 0.5 \%$ full scale, and a temperature range of $0-60^{\circ} \mathrm{C}$.

The operating controls of the indicator consist of an off/battery check/track/memory switch, charge plug, input/output jack, digital panel meter, calibration reset switch, and adjustable span and zero dial.

Table 1. Case histories of the nine patients with their depthsense thresholds as measured by two esthesiometers.

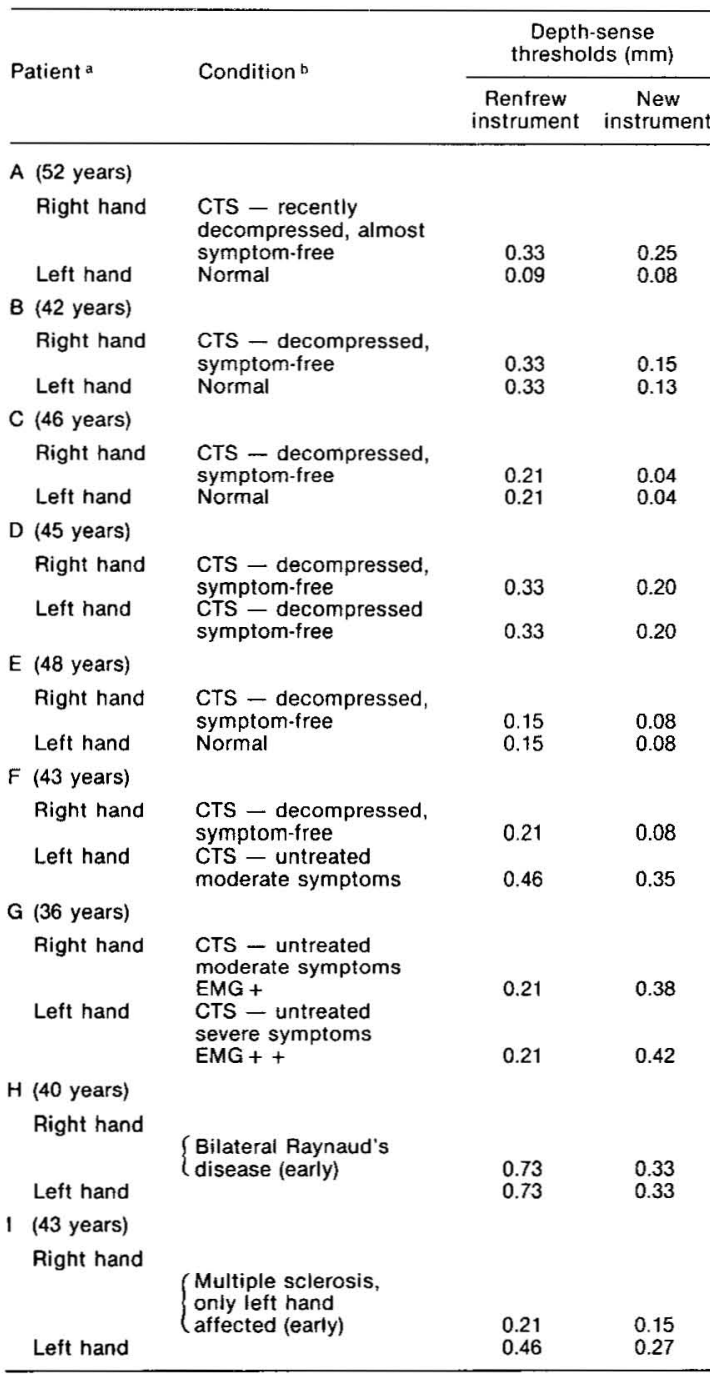

a Age of patient in parentheses.

CTS = carpal tunnel syndrome, EMG = electromyography, $+=$ early changes, $++=$ moderate changes

\section{Control box}

The control box is designed with the following features: (i) an adjustable speed control dial which is set to move the wedge at a slow, medium and fast speed, (ii) a direction-switch to control the movements of the instrument in forward and backward directions, (iii) a set of three stop/start push button switches, and (iv) three electric sockets - one for connecting it to the esthesiometer, one to the operator's handheld switch, and one to the main.

\section{Subjects}

The population for the study was divided into two main groups. Initially 66 normal hands from 33 male Caucasians with the mean age of 39.2 (SD 9.3) years were examined. Of these, five were smokers, and none had a history of neurotoxic drug intake or exposure to vibration.

Subsequently nine female subjects of mixed races with the mean age of 43.9 (SD 4.6) years were tested. Seven of these patients had a history of carpal tunnel syndrome (treated and untreated), one of primary Raynaud's disease, and one of multiple sclerosis. Among them, four were smokers, five nonsmokers, and none had any history of taking any medication. Two of the patients with carpal tunnel syndrome happened to have had electromyographic examinations in the hospital.

\section{Methods}

As a first step, the electric connections between the esthesiometer, control box, and digital peak indicator are checked, along with the calibration of the last-mentioned device. Skin temperature is recorded with a Jumo-Therm hand-held digital thermometer. If the hand temperature is low, the study does not proceed until a satisfactory temperature of above $30^{\circ} \mathrm{C}$ is established. In the present study the subjects were assigned in random order to have either the new instrument or the Renfrew instrument first in the sequence of testing by both.

The finger to be examined rests comfortably on the bridge with the terminal phalanx flexed at the distal crease. Each individual is shown how the tip of the finger midway between the center of the whorl and fingernail should touch the ridge without moving it diagonally. The pressure with which the finger contacts the wedge is maintained at a constant force equivalent to 1 pound $(0.45 \mathrm{~kg})$, as shown in the digital display with a light-emitting dial.

Next, the speed-control dial is set at the desired speed of $1 \mathrm{~mm} / \mathrm{s}$, the direction switch is moved to the right for forward movement, and the starter button is activated. When the subject indicates that the ridge has been felt, the hand-held switch is pushed by the examiner to stop the movement of the instrument, and the ridge height is read from the dial test indicator.

The direction switch is then moved to the left for reverse movement, and the operation is followed as before. The whole procedure is repeated until the dial test indicator registers the same reading at least twice for both forward and backward directions. The final figure thus obtained is recorded as the depth-sense threshold for the individual concerned.

The measurements were made for the index (2nd) and the ring (4th) fingers of both hands. As suggested by Renfrew, the cut-off point between the normal and abnormal thresholds was taken as $0.25 \mathrm{~mm}$. The testing procedure and the number of replications were the same for the Renfrew instrument. The subjects were "blind" with respect to the aim of the study, and to avoid the examiner's bias the Renfrew instrument had reference numbers instead of facilities for the direct measurement of depth sense. 


\section{Results}

Repeated examinations showed that for normal subjects there was no significant differences between the fingers or between the hands. As a result, the thresholds of depth sense measured by each instrument are expressed as a mean composite value. The threshold obtained by the new instrument was significantly lower (mean 0.09, SD 0.05) than that determined by Renfrew's instrument (mean 0.18, SD 0.09). When measured by the latter, 12 out of 66 normal hands (18\%) had abnormal results (thresholds $>0.25 \mathrm{~mm}$ ), but with the new instrument, all thresholds were within the normal range. The chi-square test confirmed that the difference between the sensitivities of the two esthesiometers was statistically highly significant $\left(\chi^{2}\right.$ 13.2, df $1, \mathrm{P}<0.01$ ).

Table 1 shows the case histories of the nine examined patients suffering from various neurovascular conditions. When tested with the Renfrew esthesiometer, six out of seven hands completely symptom-free for a significant period following surgical decompression of the carpal tunnel showed higher thresholds, four being frankly abnormal.

In comparison, with the new instrument, the values were all normal. Of the three untreated hands with carpal tunnel syndrome, only one showed abnormal thresholds with Renfrew's instrument, but all three had abnormal results with the new instrument, good correlation being shown in the two cases with electromyographic changes.

Similarly, in comparison with the new instrument, the Renfrew instrument showed thresholds that were too high for an early case of bilateral Raynaud's disease and a case of multiple sclerosis.

\section{Discussion}

The modifications made in the new instrument meet the objectives described in the Introduction. A similar study has been carried out by Carlson and his colleagues (1). They devised an esthesiometer in which the finger can be passively held at a fixed position and pressure. However, the speed and the direction of its movement could not be controlled as with the instrument presented in this report, the latter, in addition, showing a more accurate method of measuring depth sense. So far as sensitivity is concerned, the new esthesiometer seems to compare favorably with the instrument devised by Carlson et al (1).

Sivayoganathan and his co-authors (6) attempted to modify the Renfrew esthesiometer by controlling the finger pressure. From three groups of subjects, they showed that their instrument could differentiate between a group of industrial workers with stage 2 and 3 VWF $(\mathrm{N}=16)$, a reference group of industrial workers of similar age $(\mathrm{N}=10)$, and a group of students $(\mathrm{N}=25)$. In spite of this claim, as the study did not include any cases with lower stages of VWF, the cut-off point between the normal and abnormal thresholds remained indecisive.

In addition, the threshold observed for normal industrial workers seemed higher $(0.29 \mathrm{~mm})$ in comparison with that of the new instrument. If the mean plus two standard deviations obtained from testing 66 normal hands with the new instrument $(0.19 \mathrm{~mm})$ was employed as a cut-off point between the normal and abnormal hands, the results would be even more encouraging. According to this criterion only two (one subject) out of 66 normal hands would show abnormal thresholds with the new instrument but 28 with the Renfrew instrument. In conclusion, it can be stated that the new esthesiometer appears to show improved correlation for depth-sense thresholds of normal and abnormal hands.

However, whether it is useful for the objective diagnosis of VWF can only be validated by further studies, especially on subjects exposed to vibration.

\section{Acknowledgments}

I wish to thank Mr R Sheridan and Mr F Lyons for their assistance in the engineering development of the instrument, Dr SE Brill for approving the paper for publication, and Ms P Tucker for typing the manuscript.

\section{References}

1. Carlson WS, Samueloff S, Taylor W, Wasserman DE. Instrumentation for measurements of sensory loss in the fingertips. J Occup Med 21 (1979) 260-264.

2. Chatterjee DS, Barwick DD, Petrie A. Exploratory electromyography in the study of vibration induced white finger in rockdrillers. $\mathrm{Br} \mathrm{J}$ Ind Med 39 (1982) 89-97.

3. Chatterjee DS, Petrie A, Taylor W. Prevalance of vibration-induced white finger in fluorspar mines in Weardale. Br J Ind med 35 (1978) 208-218.

4. Lundstrom R, Johansson RS. Acute impairment of the sensitivity of the skin mechanoreceptive units caused by vibration exposure of the hand. Ergonomics 29 (1986) $687-698$.

5. Renfrew S. Fingertip sensation - A routine neurological test. Lancet 1 (1969) 396-397.

6. Sivayoganathan K, Akinmayowa NK, Corlett EN. Objective test for the vibration syndrome and reduction of vibration during fettling. In: Brammer AT, Taylor W, ed. Vibration effects on the hand and arm in industry. John Wiley \& Sons, New York, NY 1982, pp 325-331.

7. Taylor W, Pelmear P, Pearson JCG. Clinical objective tests for vibration white finger in industry. Academic Press, London 1975, pp 53-81. 